\title{
Comparison of Microstructure and Residual Stress Between TIG and MAG Welding Using Low Transformation Temperature Welding Filler
}

\author{
Zhong-Yuan Feng ${ }^{1,2} \cdot$ Xin-Jie Di ${ }^{1,2} \cdot$ Shi-Pin $\mathrm{Wu}^{1,2} \cdot$ Dong-Po Wang ${ }^{1,2} \cdot$ Xiao-Qian Liu ${ }^{1,2}$
}

Received: 6 June 2017/Revised: 25 July 2017/Published online: 30 August 2017

(C) The Chinese Society for Metals and Springer-Verlag GmbH Germany 2017

\begin{abstract}
A Cr-Ni type of low transformation temperature (LTT) welding filler was devised in the present study. The LTT weld microstructures of the tungsten inert gas (TIG) and metal active gas (MAG) weldings were investigated by using electron-backscattered diffraction and orientation imaging microscopy. The results showed that the LTT weld microstructures prepared by TIG and MAG weldings were primarily martensite with $17.5 \%$ and $8.0 \%$ retained austenite, respectively. The LTT weld metal using TIG welding had larger grain size than using MAG. In addition, based on the Taylor factor calculation, the weld metal using MAG welding was more competent in repressing fatigue crack initiation. Meanwhile, the high angle and coincidence site lattice grain boundaries were dominant in the LTT weld metal using MAG welding. Moreover, the hardness of the LTT weld metal using MAG welding was higher than that of using TIG. Based on heat input and phase transformation, finite element method was applied to analyzing the tensile residual stress (RS) reduction in welded joints prepared by both conventional and LTT welding fillers, respectively. The corresponding outcome confirmed that the LTT weld metal using MAG welding was more beneficial to tensile RS reduction.
\end{abstract}

KEY WORDS: Martensitic transformation; Taylor factor; Grain boundaries; Residual stress

\section{Introduction}

Tensile residual stress (RS) is known to be detrimental to the fatigue strength of welded joints [1]. Using low transformation temperature (LTT) welding fillers, however, numerous studies have demonstrated that the RS state in welded joints can be reversed from tensile to compressive, improving the fatigue strength of welded joints [2-5]. Although LTT weld metals are competent in generating lower RS in welded

Available online at http://link.springer.com/journal/40195.

Xin-Jie Di

dixinjie@tju.edu.cn

1 School of Materials Science and Engineering, Tianjin University, No. 135 Yaguan Road, Jinnan District, Tianjin 300350, China

2 Tianjin Key Laboratory of Advanced Joining Technology, Tianjin 300350, China joints, the toughness of the LTT weld metals is rather low, which limits its application to welding engineering [6]. Therefore, how to improve the comprehensive properties of the LTT welded joints is still in research state so far.

As a joining technique, tungsten inert gas (TIG) welding, due to its greater requirement to control the welded area, is characterized by its advantage of excellent joining quality [7]. Using LTT welding filler, weld toe treatment using TIG dressing has been shown to be capable of improving the fatigue properties of welded joints to some degree $[8,9]$. In addition, it is found that TIG welding has a great influence on phase transformation behavior and mechanical properties of welded joints [10]. As aforementioned, LTT welding filler does well in fatigue performances but poorly in toughness [6]. How the application performance of the LTT welding fillers applied to surface welding or cosmetic welding using TIG welding with relatively high heat input will be, still needs to be emphasized and investigated. 
In general, the durability of welded structures and application performance are significantly dependent on the fatigue-resistant microstructure of LTT weld metal. To elucidate the fatigue-resistant microstructure, EBSD technique is a practical tool for microscopic investigation. Grain size, Taylor factor and attendant grain boundaries characterized by EBSD technique can make a dramatic impact on the fatigue properties of components. According to Davidson and Chan [11], fatigue crack initiation for coarse-grain Astroloy took place with low values of the Taylor factor. In addition, grain boundary engineering based on the notion of "grain boundary design and control" has been targeting at promoting the practical application of structural materials [12, 13].

As aforementioned, RS plays a significant role in the fatigue strength of welded joints. The finite element method (FEM) analysis applied to simulating the welding process offers a great advantage in predicting RS. Generally, FEM software takes into account material properties, welded joint design and welding methods to control and optimize welding procedure. Research has showed that FEM analysis of LTT welded joint is effective and efficient and also decreases requirement for physical prototypes with a cost and time reduction [14].

In this study, a Cr-Ni type of LTT welding filler was devised. Comparisons of microstructures and RS of LTT welded joints between TIG and metal active gas (MAG) welding were made. Accordingly, grain size, Taylor factor and attendant grain boundaries were demonstrated by means of EBSD and orientation imaging microscopy (OIM) techniques. Meanwhile, RS in welded joint was analyzed using the FEM analysis.

\section{Experimental}

Using the identical LTT welding filler, two surfacing joints, according to the standard methods specified in ASME BPVC. II.C-2015, were prepared by using TIG and MAG weldings, respectively. The welding conditions are summarized in Table 1. The chemical compositions of the LTT weld metals using different welding methods are listed in Table 2. The compositions of LTT weld metals vary with heat input and shielding gas.
To identify the martensite start $(M \mathrm{~s})$ temperature of the LTT weld metals, dilatometric test was carried out by utilizing a Gleeble 3500 thermo-mechanical simulation system. As depicted in Fig. 1, cylindrical samples of $6.0 \mathrm{~mm}$ in diameter and $70 \mathrm{~mm}$ in length were extracted from surfacing metals. Figure 2 shows the simulated welding thermal cycle for the LTT samples which were heated to $1350{ }^{\circ} \mathrm{C}$ at the rate of $100{ }^{\circ} \mathrm{C} / \mathrm{s}$ and then held for $1.5 \mathrm{~s}$, followed by continuous cooling to ambient temperature. The LTT weld microstructures were observed by optical microscope, EBSD and OIM techniques. In addition, the hardness of the LTT weld metals was measured based on ASTM A370-17.

\section{Results and Discussion}

\subsection{Ms Temperature and Microstructure}

Comparative study of phase transformation between LTT samples using different welding methods was conducted under the same condition of the welding thermal curve. Figure 3 depicts the dilatometric curves of the LTT weld metals using TIG and MAG weldings, respectively. The dilatometric measurement determined the $M$ s temperature as the temperature at which the slope changed from positive to negative during cooling. As can be seen in Fig. 3, both of the LTT weld metals had a similar Ms temperature around $125^{\circ} \mathrm{C}$, in which martensitic transformation had occurred. However, the LTT weld metals using different welding methods exhibited different volume expansion, shedding light on the martensitic transformation degree. In addition, the amount of elongation $(+0.17 \%)$ of the LTT weld metal using TIG welding was lower than that of using MAG $(+0.46 \%)$. What is more, the cooling curve of dimensional change of weld metal using MAG welding showed a slight negative (shrinkage) value in comparison with that of using TIG. By comparing the volume expansion and dimensional change, it can be concluded that the LTT weld metal using MAG welding is beneficial to tensile RS reduction. However, it should be noted that both of the LTT weld metals possess $\delta$-ferrite at elevated temperature. When the weld metal containing $\delta$-ferrite is held at an elevated temperature, $\delta$-ferrite will transform into

Table 1 Welding parameters for LTT welding filler using different welding methods

\begin{tabular}{llllll}
\hline Welding method & Shielding gas & Average current $(\mathrm{A})$ & Average voltage $(\mathrm{V})$ & Welding speed (mm/min) & Heat input $(\mathrm{kJ} / \mathrm{mm})$ \\
\hline TIG & $\mathrm{Ar}$ & 120 & 12.0 & 50 & 1.73 \\
MAG & $80 \% \mathrm{Ar}+20 \% \mathrm{CO}_{2}$ & 290 & 26.4 & 300 & 1.53 \\
\hline
\end{tabular}


Table 2 Chemical composition of LTT weld metals using different welding methods (wt\%)

\begin{tabular}{llllllll}
\hline Welding method & $\mathrm{C}$ & $\mathrm{Mn}$ & $\mathrm{Cr}$ & $\mathrm{Ni}$ & $\mathrm{Mo}$ & $\mathrm{Si}$ & $\mathrm{Fe}$ \\
\hline TIG & 0.017 & 1.17 & 11.10 & 8.90 & 0.14 & 0.30 & $\mathrm{Bal}$. \\
MAG & 0.025 & 1.04 & 11.95 & 9.23 & 0.14 & 0.39 & $\mathrm{Bal}$. \\
\hline
\end{tabular}

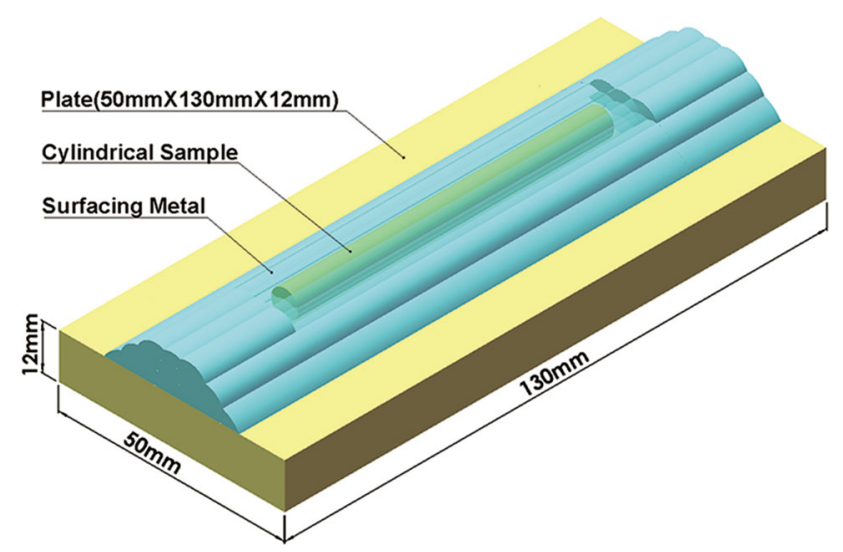

Fig. 1 Schematic drawing of cylindrical sample in surfacing joint

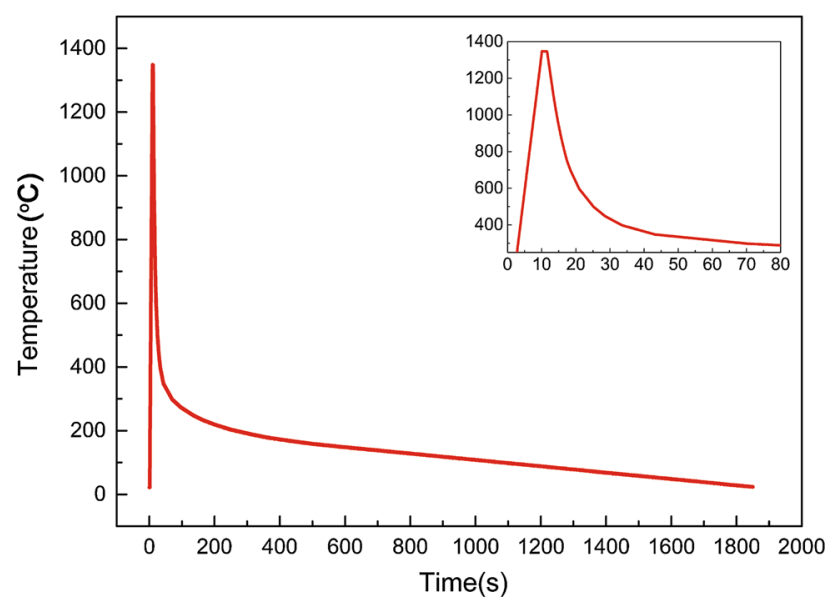

Fig. 2 Simulated welding thermal cycle for LTT weld samples

austenite, naturally inducing tensile stress in welded joint [15]. Due to different heat input and shielding gas during welding, the chromium/nickel equivalent $\left(\mathrm{Cr}_{\mathrm{eq}} / \mathrm{Ni}_{\mathrm{eq}}\right)$ ratio, the ratio of the amount of ferrite stabilizing elements to the austenite stabilizing elements, led to different $\delta$-ferrite transformations between the LTT weld metals. The $\mathrm{Cr}_{\mathrm{eq}} /$ $\mathrm{Ni}_{\mathrm{eq}}$ ratio derived from the Schaeffler formulation [16]. The calculated $\mathrm{Cr}_{\mathrm{eq}} / \mathrm{Ni}_{\mathrm{eq}}$ ratios for LTT weld metal using TIG and MAG were 1.17 and 1.21, respectively. LTT weld metal using TIG therefore accompanied with lower $\delta$-ferrite content. Ironically, the higher the heat input is, the larger the thermal stress induces. Therefore, how to adjust the heat input plays a significant role in tensile RS reduction.

Figure 4 presents the microstructural morphologies of the LTT weld metals using different welding methods. Both of the LTT weld microstructures revealed a martensitic matrix with intercellular retained austenite (RA). The amount of RA within the LTT weld metal was determined by means of EBSD and OIM techniques. It can be seen evidently from Fig. 5 that the phase proportion varied with the usage of different welding methods. Higher percentage of RA up to $17.5 \%$ was found in the LTT weld using TIG welding, while LTT weld metal using MAG welding contained lower amount of RA about $8.0 \%$, which accorded with the dilatometric results.

\subsection{Taylor Factor, Grain Boundaries and Hardness}

The LTT welded joint using TIG welding had higher heat input than that using MAG, resulting in the grain size of LTT weld metal using TIG welding bigger than that of using MAG, as shown in Fig. 6. According to the HallPatch definition of grain boundary strengthening [17], grains with small size are competent in impeding dislocation movement from grain to grain, heightening the yield strengthen of materials.

Specifically speaking, fatigue process of metallic materials without macroscopic defects consists of crack initiation, crack propagation and final unstable fracture [18]. As to the former, fatigue crack initiation can be evoked under the circumstance of irreversible process of extrusion and intrusion through slip deformation. To analyze the tendency of slip deformation, Taylor factor was computed on the basis of orientation and the given loading direction. According to Azae et al. [19], Taylor factor estimated the generic conditions of the deformed grain under a nonuniform multi-axial stress state of each grain to allow multi-slip phenomenon. In general, grains with low Taylor factor are suitable for dislocation slip, while high Taylor factor are considered to be less likely to yield and might be subject to transgranular fracture [20,21]. Figure 7 shows the Taylor factor mapping across the scanned area. The fraction of red area is indicative of difficulty in inducing slip deformation within grains. There is no doubt that LTT weld metal using MAG welding was more likely to hinder slip deformation, upgrading the fatigue properties of welded joint in accordance with Kimura et al. [22].

Taking advantage of EBSD and OIM techniques, comparative result of the misorientation angle distribution is depicted in Fig. 8. As can be seen, LTT weld metal using TIG welding had higher number fraction of low angle boundaries with misorientation below $15^{\circ}$ than that using MAG. In other words, high angle boundaries was found to 

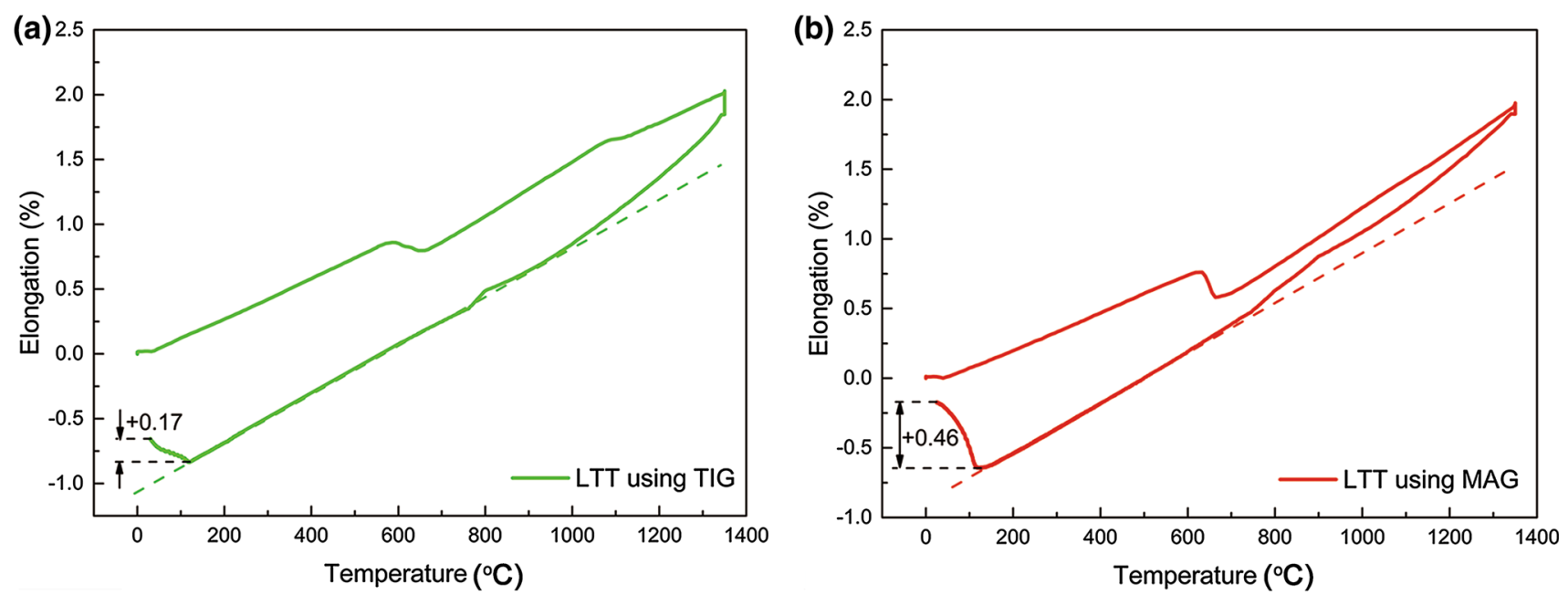

Fig. 3 Dilatometric curves of LTT weld metals using a TIG; b MAG weldings
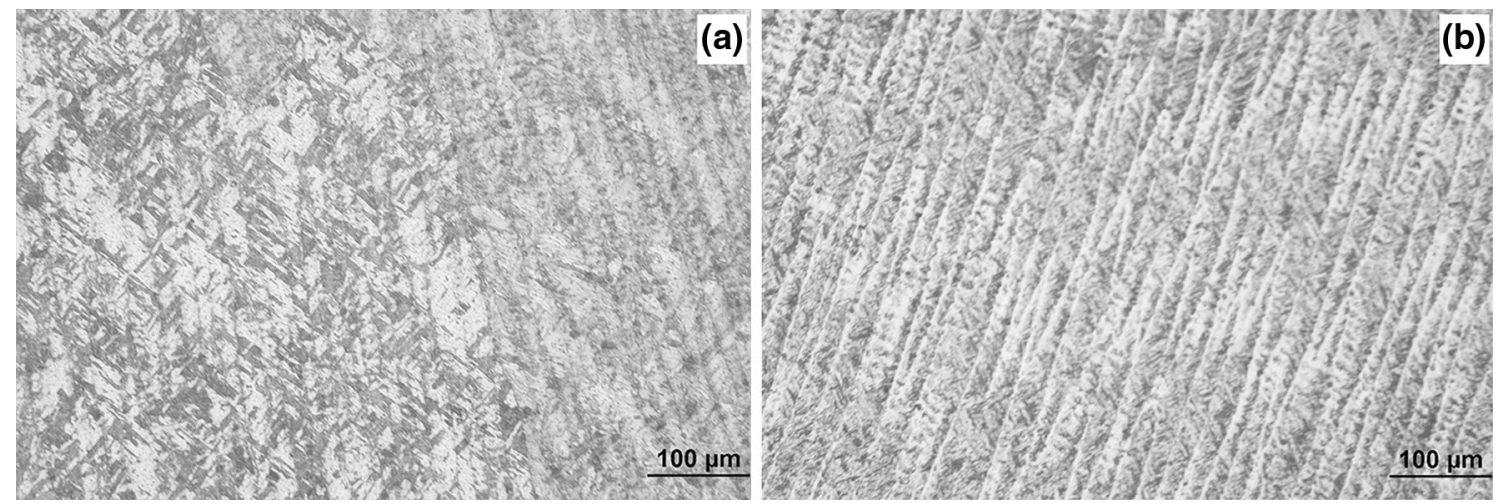

Fig. 4 OM micrographs of LTT weld metals using a TIG; b MAG weldings
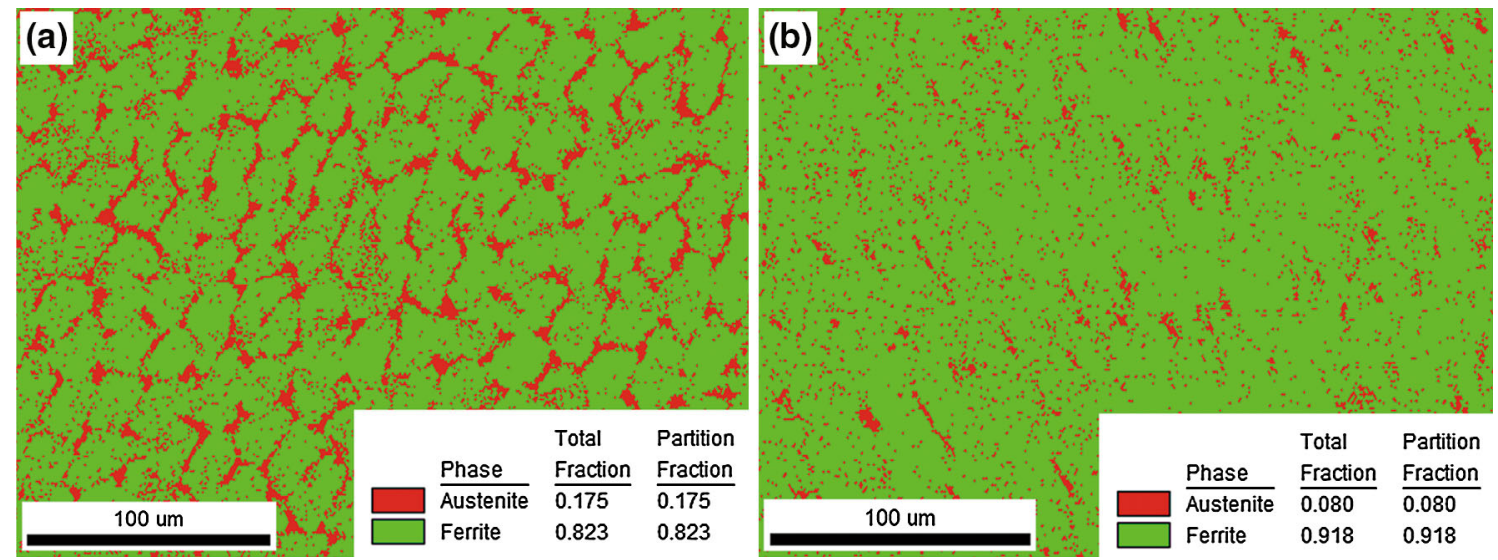

Fig. 5 Phase fraction of LTT weld metals using a TIG; b MAG weldings

be dominant in LTT weld metal using MAG welding. Since the grain size of LTT weld metal using TIG welding was large, the embedded grain boundary length was consequently shorter than that of using MAG welding. By and large, the prior austenite grain boundaries accompany with misorientation above $15^{\circ}$ (below $45^{\circ}$ ), whereas misorientation above $45^{\circ}$ is associated with the "martensite lath packet" boundaries [23]. As mentioned above, the amount of RA of LTT using TIG welding was high compared to that of using MAG so that plenty of grain boundaries with 
misorientation above $15^{\circ}$ (below $45^{\circ}$ ) were presented in the LTT weld metal using TIG. Likewise, a great number of grain boundaries with misorientation above $45^{\circ}$ were manifested in the LTT weld metal using MAG welding.

As aforementioned, high grain angle boundaries are beneficial to the strength of crystalline materials due to repression of dislocation motion under monotonic loading. However, high angle grain boundaries have been investigated to be the preferential fatigue cracking site because of stress concentration and strain incompatibility caused by dislocation pileups [24]. Through manipulating the grain

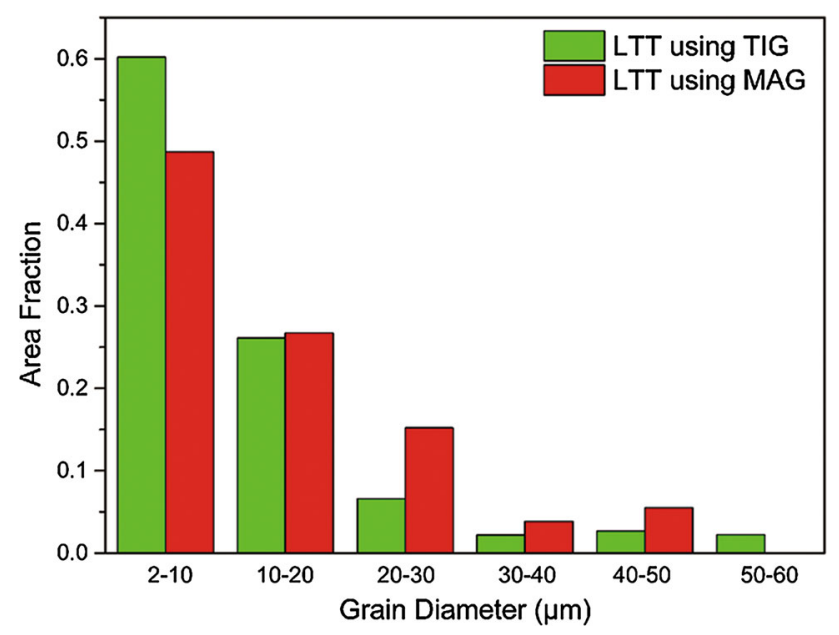

Fig. 6 Comparison of grain size of LTT weld metals using different welding methods

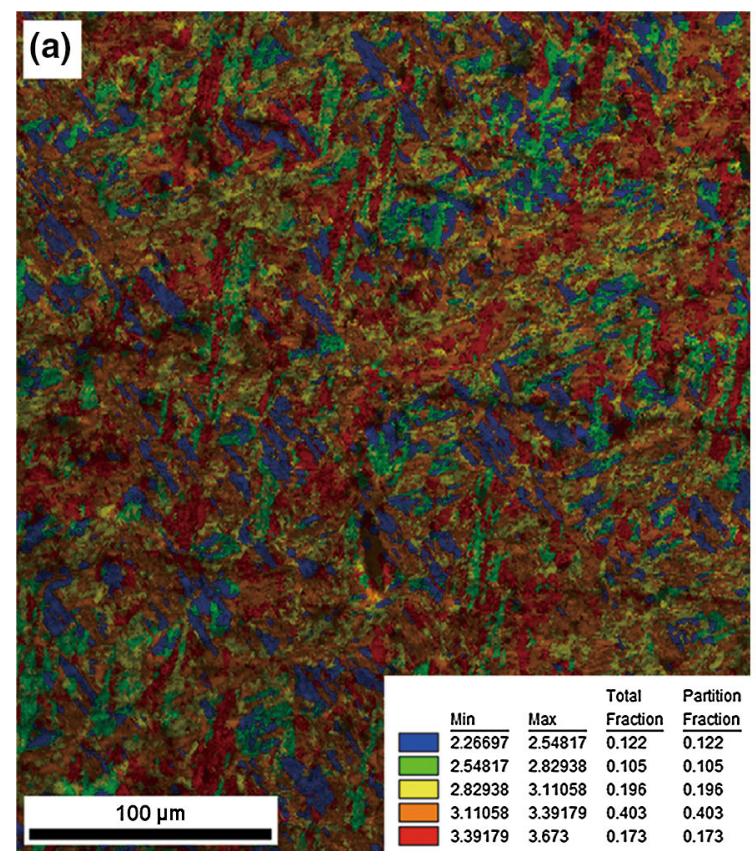

boundaries configuration, increasing the number fraction of coincidence site lattice (CSL) grain boundaries with $\Sigma$ value $\leq 29$ will be of benefit to lower propensity to intergranular fracture [25]. Figure 9 shows CSL grain boundaries of LTT samples using different welding methods. Evidently, LTT weld metal using MAG welding had higher number fraction of CSL grain boundaries in total than using TIG. As CLS grain boundaries possess low energy and high mobility characteristics, LTT weld microstructures with higher CSL grain were advantageous to resisting fatigue crack propagation $[13,26]$.

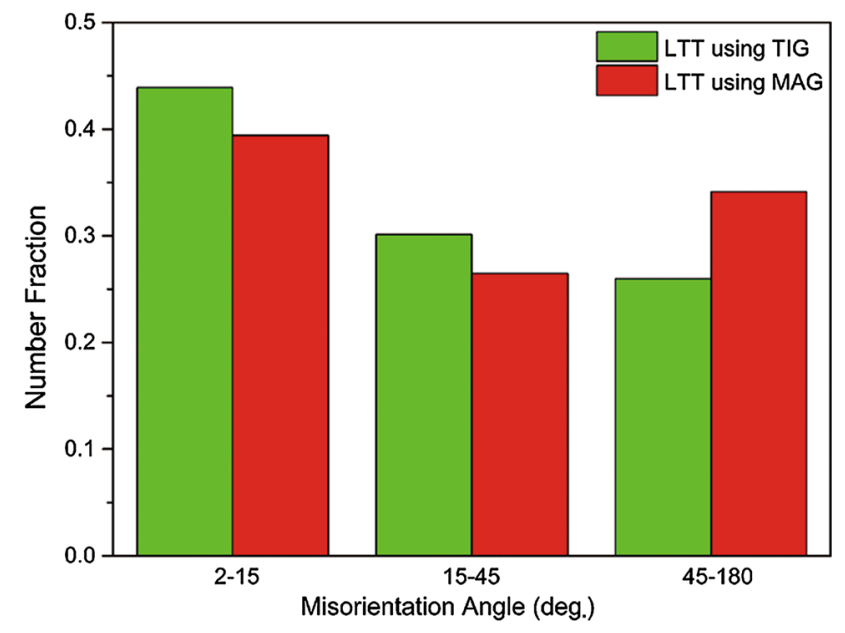

Fig. 8 Misorientation angle distribution of LTT weld metals using different welding methods

Fig. 7 Taylor factor mapping of LTT weld metals using a TIG; b MAG weldings 


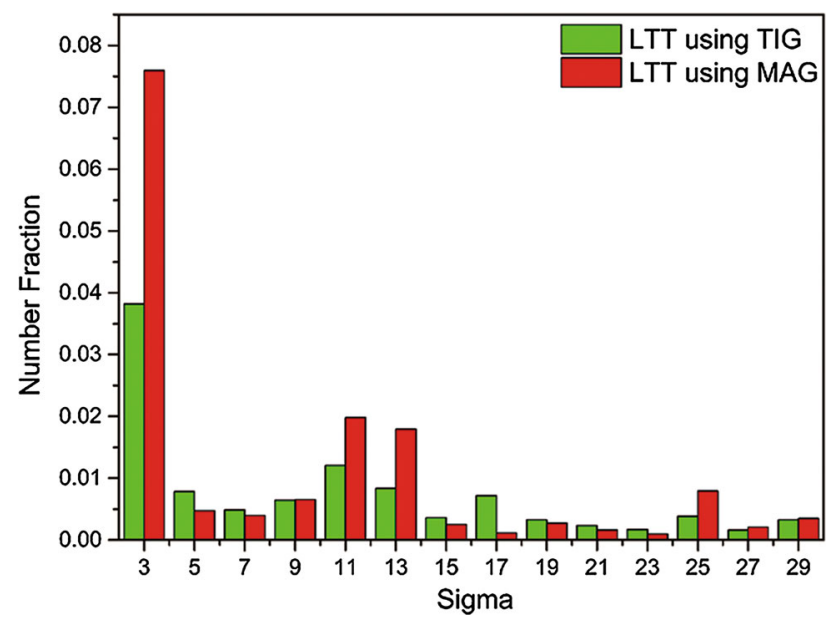

Fig. 9 CSL grain boundaries of LTT weld metals using different welding methods

Both of the LTT samples were subjected to the Vickers hardness test. The hardness test results of the LTT weld metals using TIG and MAG welding were 304 (HV10) and 323 (HV10), respectively. As shown in Table 2, LTT weld metal using MAG welding had higher carbon content than using TIG. Basically, when MAG welding is selected, the gas mixture containing carbon dioxide will improve the carbon content of the weld metal. In addition, the grain size of LTT weld metal using MAG welding was more refiner than using TIG, increasing the subsequently average hardness as well. Furthermore, a higher proportion of martensite within the weld also contributed to enhancement in hardness. As the application performance of surfacing metal can be characterized by hardness, higher hardness in a proper range reflected better abrasion resistance.

\subsection{FEM Analysis of Residual Stress (RS)}

As LTT welding filler does well in fatigue performances but poorly in toughness, LTT welding filler can be therefore applicable to surface welding or cosmetic welding to exert its comprehensive fatigue performance. For reasons of evaluating the capacity of tensile RS reduction utilizing the LTT welding filler in welding engineering, a comparison of RS between the conventional and LTT welded joints was performed by means of FEM analysis. Figure 10 depicts the FEM model in which cosmetic welding was substituted for surface welding so as to vividly exhibit the stress state in welded joint. Under the condition of constraint, a plate of $100 \mathrm{~mm} \times 180 \mathrm{~mm} \times 8 \mathrm{~mm}$ was deposited with two welding layers along the central line. The mesh size around the weld metal was $0.8 \mathrm{~mm}$ in the FEM analysis. Coarser meshes increasing away from seam zone can be adopted to obtain well accuracy as well as rational computing time.
A coupled thermo-elastic-plastic-metallurgic finite element computational procedure was applied to predicting the development of RS in welded joint. In dealing with FEM analysis, elastic strain $\varepsilon^{\mathrm{e}}$, plastic strain $\varepsilon^{\mathrm{p}}$, thermal strain $\varepsilon^{\text {th }}$ and phase transformation strain $\varepsilon^{\text {tr }}$ during welding process are taken into consideration for welded joint. Therefore, the total strain can be expressed as:

$\varepsilon^{\mathrm{e}}=\varepsilon^{\mathrm{e}}+\varepsilon^{\mathrm{p}}+\varepsilon^{\mathrm{th}}+\varepsilon^{\mathrm{tr}}$.

According to Goldak et al. [27], Gaussian and double ellipsoid heat source model were applied to simulating the complicated physics of heat generation in welded joints using TIG and MAG weldings, respectively. The material properties of the conventional weld metal were the same as the parent metal S690QL steel originating from the material library of numerical software. As regards the material properties of LTT weld metals, the yield strengths for both of the LTT metals at ambient temperature were 340 and $420 \mathrm{MPa}$, respectively, while the yield strengths at higher temperature and temperature-dependent values of Young's modulus were calculated using thermodynamic software JMatPro ${ }^{\circledR}$. The Poisson's ratio was set to 0.3 for the LTT weld metals. The thermal expansion coefficients of austenite and martensite were assumed to be $2.2 \times 10^{-5} \mathrm{~K}^{-1}$ and $1.5 \times 10^{-5} \mathrm{~K}^{-1}$, respectively [28]. Densities for austenite and martensite were set to the identical value $7290 \mathrm{~kg} / \mathrm{mm}^{3}$ at $1400{ }^{\circ} \mathrm{C}$, and yet 7966 and $7680 \mathrm{~kg} / \mathrm{mm}^{3}$ at ambient temperature, respectively. Figure 11 presents the temperature-dependent thermal physical properties applied to the FEM model. Some of these physical properties like specific heat capacity and thermal conductivity were determined from previous research work as a Refs. [29, 30]. Three simulation cases with its numerical welding conditions are summarized in Table 3. The numerical welding parameter of cosmetic welding is identical to that of the aforementioned surface welding.

Figure 12 depicts the nodal RS derived from the FEM analysis along the yellow line as shown in Fig. 10. In case of the conventional welded joint, as shown in Fig. 12a, conspicuous tensile RS exceeding $600 \mathrm{MPa}$ is observed in the longitudinal direction. On the contrary, the LTT welds produced significant compressive RS in welded joints. Based on the above-mentioned heat input and martensitic transformation, lower compressive RS up to $200 \mathrm{MPa}$ was generated in the LTT welded joint using MAG welding. In addition, it is evident that transformation-related tensile RS maxima were generated in the heat-affected zone. Due to volume expansion in the transverse direction, the transverse RS is characterized by a relatively lower stress level as shown in Fig. 12b. The conventional weld brought about tensile RS about $50 \mathrm{MPa}$, while both LTT welds were 


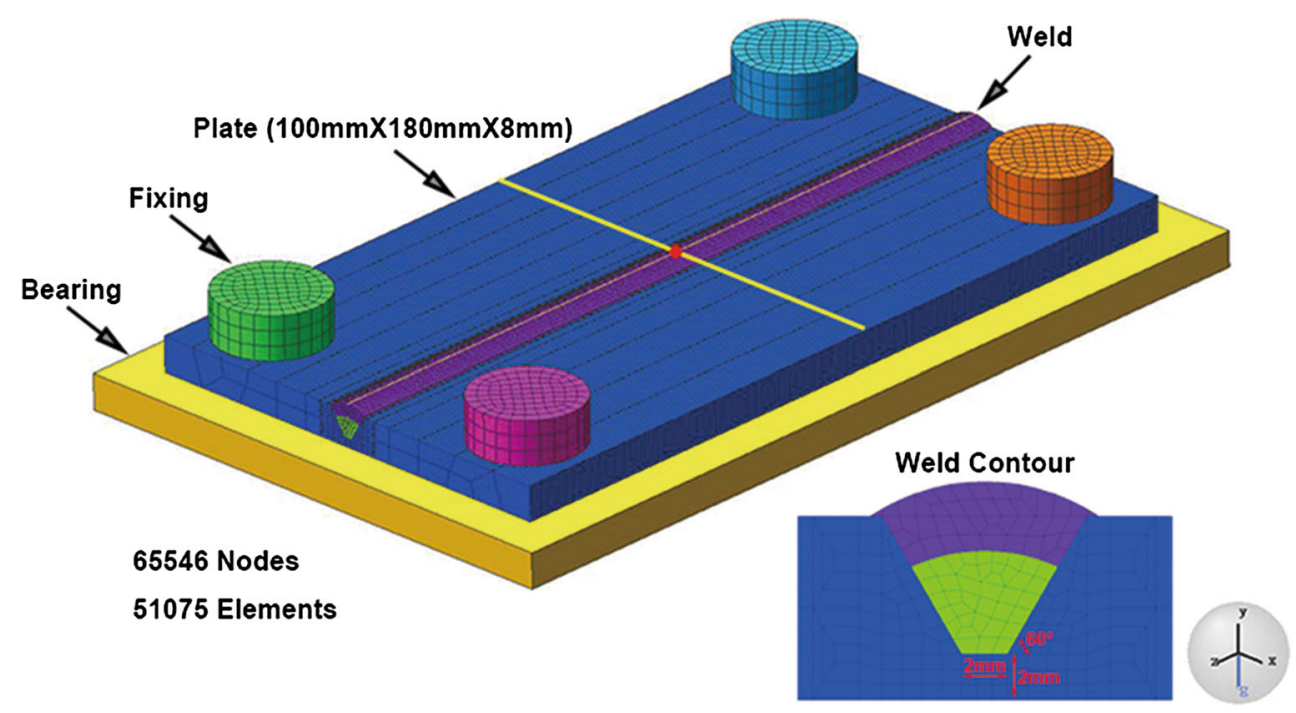

Fig. 10 Finite element model applied to simulate residual stress
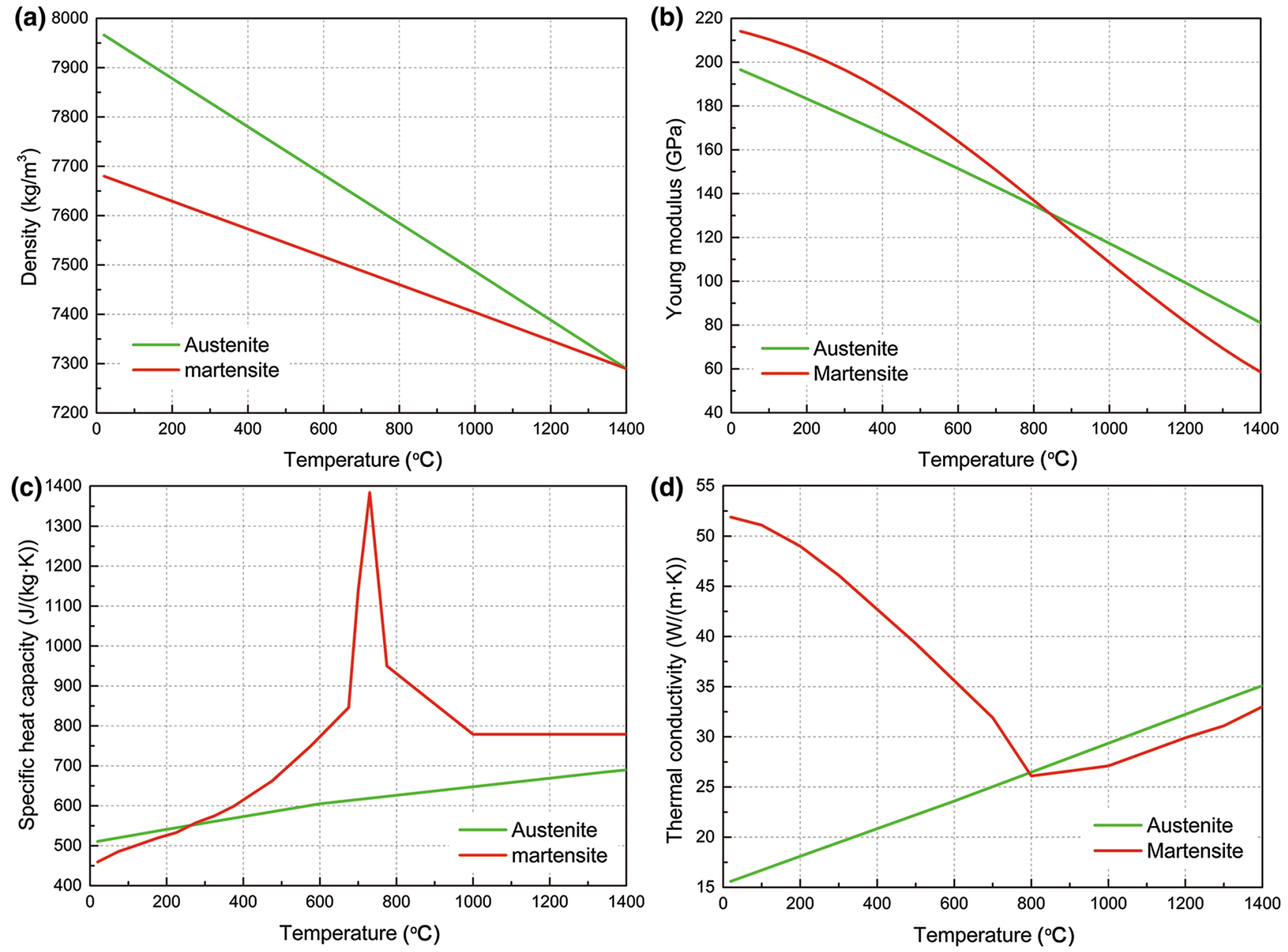

Fig. 11 Temperature-dependent thermal physical properties of LTT weld metals [29, 30] 
Table 3 Welding parameters of simulation cases considered in the FEA analysis

\begin{tabular}{lllllll}
\hline Case & Welding layer & Welding filler & Welding method & Average current (A) & Average voltage (V) & Welding speed (mm/min) \\
\hline 1 & First & The conventional & MAG & 260.0 & 24.5 & 300 \\
& Second & The conventional & MAG & 290.0 & 26.4 & 300 \\
2 & First & The conventional & MAG & 260.0 & 24.5 & 300 \\
& Second & The LTT & TIG & 120.0 & 12.0 & 50 \\
\multirow{2}{*}{3} & First & The conventional & MAG & 260.0 & 24.5 & 300 \\
& Second & The LTT & MAG & 290.0 & 26.4 & 300 \\
\hline
\end{tabular}
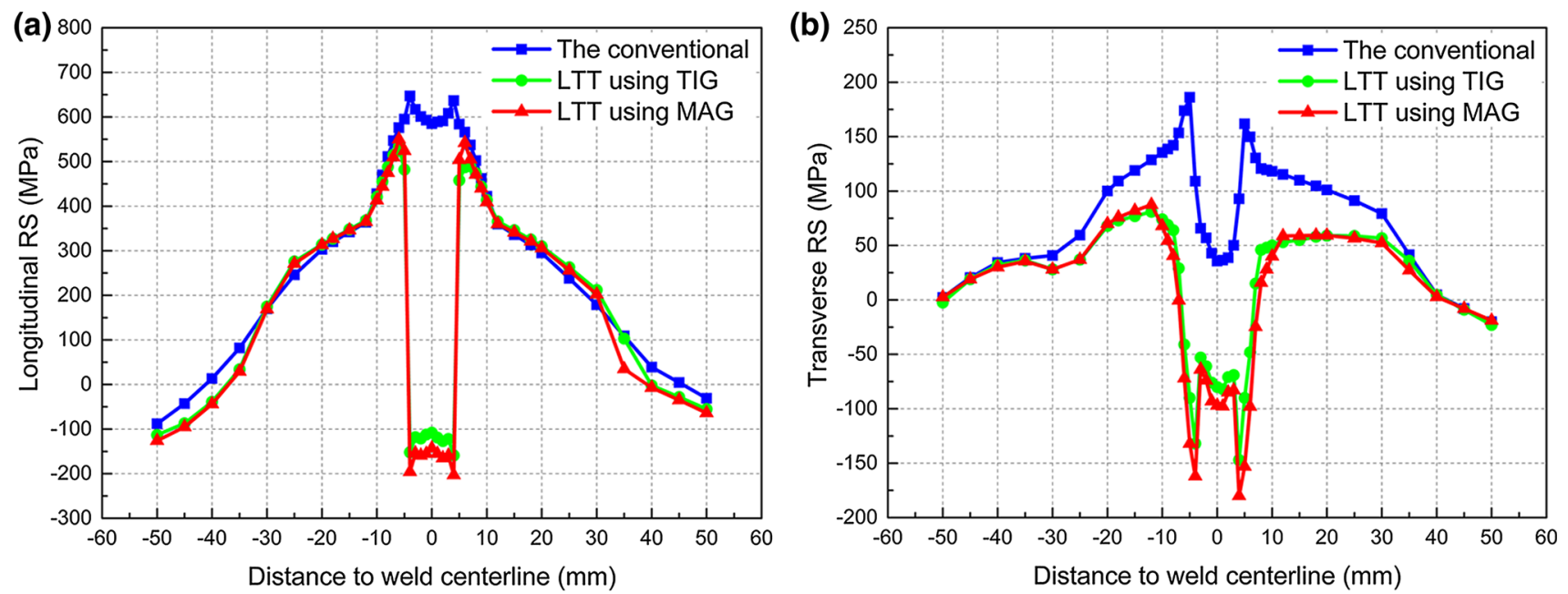

Fig. 12 Longitudinal and transverse RS of the conventional and LTT welded joints

characterized by compressive RS. Moreover, compressive RS up to $180 \mathrm{MPa}$ was produced in the LTT welded joint using MAG welding, which proved again that LTT weld metal using MAG welding was beneficial to tensile RS reduction. Besides, the results agreed with the previous work done by Francis et al. [31].

Figure 13 depicts the nodal RS evolution with time for three simulation cases. Welding time for each welding layer was $36 \mathrm{~s}$, and the total welding time was $72 \mathrm{~s}$ in the FEM model. The nodal longitudinal RS (denoted by black line) was calculated at the red node located in the midsection of second weld bead as shown in Fig. 10 so that the start time of the nodal welding corresponded to $54 \mathrm{~s}$. As to the first simulation case as shown in Fig. 13a, the tensile RS initially developed due to thermal strains between the solidified weld and the adjacent parent metal. Whereafter, transformation from austenite to bainite occurred as the temperature reached the bainite start point corresponding to $100 \mathrm{~s}$, which counteracted and decreased the shrinkagerelated stress because of the transformation strain [32]. However, tensile RS was accumulating subsequently once the bainite transformation completed. Similarly, the tensile
RS of the LTT simulation cases as shown in Fig. 13b, c was induced in weld metal at the beginning. Taking into account the first welding layer deposited by the conventional welding filler, bainitic transformation occurred just like the first simulation case and a slight RS reduction was presented at welded node. In addition, the tensile RS increased as well when the bainitic transformation of the first welding layer finished. However, tensile RS reduction dramatically occurred when the LTT weld cooled to the Ms temperature corresponding to $216 \mathrm{~s}$. Unlike the conventional weld metal, the longitudinal RS at the LTT weld note decreased gradually with the continuous martensitic transformation, resulting in compressive RS dwelled in welded joint. The distinction of tensile RS reduction between LTT weld metals using different welding methods was ascribed to the aforementioned heat input and can be vividly verified in Fig. 13b, c. The welded note at the LTT weld metal using TIG welding had higher temperature and lower martensitic transformation than that of using MAG, leading to relatively lower tensile RS reduction as a consequence. In short, the numerical results demonstrated that not only martensitic transformation in a proper temperature 

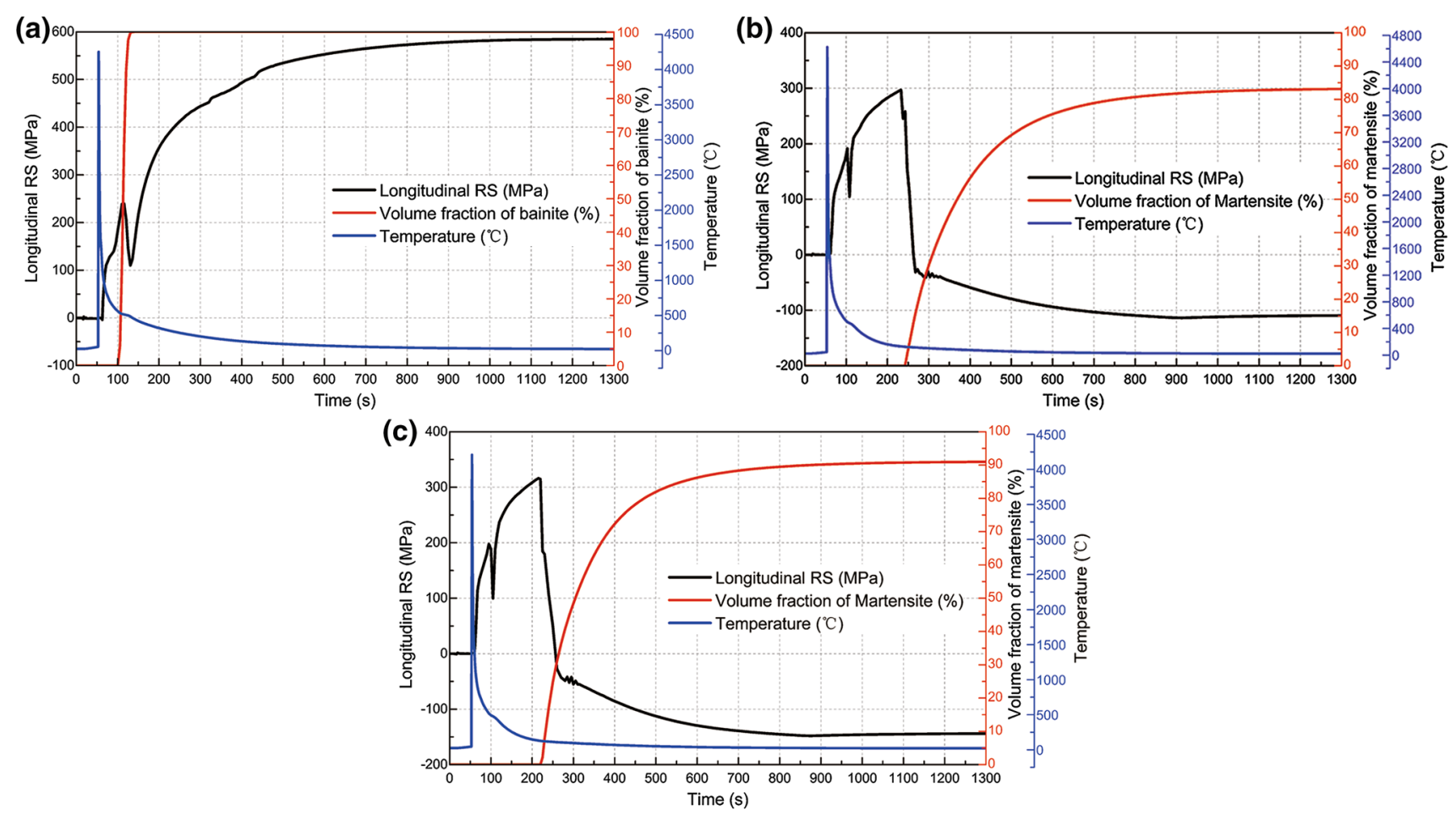

Fig. 13 Computed longitudinal RS, phase fraction and temperature as function of time at welded node: a the conventional; b LTT using TIG; c LTT using MAG

range was beneficial to tensile RS reduction, but also LTT weld metal using MAG welding was more appreciative in terms of heat input.

\section{Conclusions}

Based on the experimental and numerical results from the LTT welding filler using different welding methods, several conclusions can be drawn as follows:

1. Volume expansion due to martensitic transformation varied with the LTT weld metals utilizing different welding methods. The volume expansion rates of LTT weld metal using TIG and MAG were $0.17 \%$ and $0.46 \%$, respectively.

2. Both the LTT weld metals had a similar martensite start temperature of about $125{ }^{\circ} \mathrm{C}$. Due to different phase transformation degree, the microstructures of LTT weld metals fabricated by TIG and MAG welding were mainly martensite with $17.5 \%$ and $8.0 \%$ retained austenite, respectively.

3. Compared to LTT weld metal using TIG welding, LTT weld metal using MAG welding had refiner grain size. In addition, the Taylor factor calculated, high angle and CSL grain boundaries measured suggested that LTT weld metal using MAG welding had relatively perfect fatigue properties. Moreover, the hardness measured in LTT weld metal using MAG welding was higher than that of using TIG.

4. The application of LTT welding filler had a significant potential to alter the inherent residual stress developed during welding, resulting in compressive residual stress within the weld metal as predicted by FEM analysis. Taking into consideration heat input and martensitic transformation, the LTT weld metal using MAG welding was more competent in tensile RS reduction, compared to the LTT one using TIG.

Acknowledgements This project is supported by National Natural Science Foundation of China (Grant No. 51774213).

\section{References}

[1] T. NitschkePagel, H. Wohlfahrt, Mater. Sci. Forum 404, 215 (2002)

[2] L.X. Huo, D.P. Wang, W.X. Wang, Y.F. Zhang, Weld. World 48, 34 (2004)

[3] C. Miki, M.T. Hanji, M.K. Tokunaga, Weld. World 56, 40 (2013)

[4] M. Miyata, J. Jpn. Weld. Soc. 85, 207 (2016)

[5] E. Harati, L. Karlsson, L.E. Svensson, K. Dalaei, Int. J. Fatigue 97, 39 (2017)

[6] S.W. Ooi, J.E. Garnham, T.I. Ramjaun, Mater. Des. 56, 773 (2014)

[7] C. Xu, G.G. Sheng, H. Wang, K. Feng, X. Yuan, J. Mater. Sci. Technol. 32, 167 (2016)

[8] L.X. Huo, D.P. Wang, Y.F. Zhang, Int. J. Fatigue 27, 95 (2005) 
[9] L.Y. Xu, Y.F. Wang, H.Y. Jing, Y.D. Han, Sci. Technol. Weld. Join. 19, 664 (2014)

[10] L.F.A. Rodrigues, F.A. Amorim, Mrs Online Proc. Librar. 176, 153 (2015)

[11] D.L. Davidson, K.S. Chan, Metallography 37, 1089 (1989)

[12] Y.P. Zong, L. Zuo, J. Mater. Sci. Technol. 19, 97 (2003)

[13] S. Kobayashi, M. Hirata, S. Tsurekawa, T. Watanabe, Procedia Eng. 10, 112 (2011)

[14] J. Yamamoto, K. Hiraoka, M. Mochizuki, Sci. Technol. Weld. Join. 15, 104 (2013)

[15] J. Elmer, D. Olson, D. Matlock, Weld. J. 61, 293 (1982)

[16] A.L. Schaeffler, Metal Prog. 106, 227 (1974)

[17] N. Hansen, Scr. Mater. 51, 801 (2004)

[18] O. Umezawa, M. Morita, T. Yuasa, S. Morooka, Y. Ono, T. Yuri, Acta Metall. Mater. 1574, 34 (2014)

[19] A.S. Azar, L.E. Svensson, B. Nyhus, Int. J. Fatigue 77, 95 (2015)

[20] Y.D. Liu, C.G. Wang, Q.W. Jiang, T. He, L. Zuo, J. Mater. Sci. Technol. 23, 689 (2007)

[21] M. Liu, C.D. Yang, G.H. Cao, A.M. Russell, Y.H. Liu, X.M. Dong, Mater. Sci. Eng. A 671, 244 (2016)
[22] H. Kimura, Y. Wang, Y. Akiniwa, K. Tanaka, Jpn. Soc. Mech. Eng. 1, 149 (2005)

[23] X.P. Ma, L.J. Wang, C.M. Liu, S.V. Subramanian, Mater. Sci. Eng. A 539, 271 (2012)

[24] L.L. Li, Z.J. Zhang, P. Zhang, Z.G. Wang, Z.F. Zhang, Nat. Commun. 5, 3536 (2014)

[25] D.G. Brandon, Acta Metall. 14, 1479 (1966)

[26] F. Shi, X.W. Li, Y.T. Hu, C. Su, C.M. Liu, Acta Metall. Sin. (Engl. Lett.) 26, 497 (2013)

[27] J. Goldak, A. Chakravarti, M. Bibby, Metall. Mater. Trans. B 15, 299 (1984)

[28] S. Zenitani, N. Hayakawa, J. Yamamoto, K. Hiraoka, Y. Morikage, T. Kubo, K. Yasuda, K. Amano, Sci. Technol. Weld. Join. 12, 516 (2013)

[29] S.A.J. Jahromi, A. Khajeh, B. Mahmoudi, Mater. Des. 34, 857 (2012)

[30] T. Alghamdi, S. Liu, Weld. J. 93, 458 (2014)

[31] J.A. Francis, H.J. Stone, S. Kundu, R.B. Rogge, H.K.D.H. Bhadeshia, P.J. Withers, in Proceedings of 2007ASME Pressure Vessels and Piping Division Conference, San Antonio, TX, USA, 22-26 July 2007

[32] A. Kromm, J. Dixneit, T. Kannengiesser, Weld. World 58, 729 (2014) 